\title{
Mediador Game: Um jogo baseado em processo de negócio para treinamento organizacional
}

\author{
Thayná Gomes ${ }^{1}$, Tatiane Neves Lopes ${ }^{2}$, Renata Araujo ${ }^{1,2}$ \\ ${ }^{1}$ Faculdade de Computação e Informática - Universidade Presbiteriana Mackenzie \\ (UPM) São Paulo, SP - Brasil \\ ${ }^{2}$ PPgSI, Escola de Artes, Ciências e Humanidades - Universidade de São Paulo \\ (USP)São Paulo, SP - Brasil \\ \{thayna.gomes9@hotmail.com, tatiane.n.lopes@usp.br, \\ rma.renata.araujo@gmail.com\}
}

\begin{abstract}
This work presents the development of the Mediador Game, a digital game based on business processes to support business process training, applied in the mediation of conflicts of the judiciary. The game was designed using the Play Your Process method, developed in previous research, which describes the steps to transform elements of business process models into game design elements.
\end{abstract}

Resumo. Este trabalho apresenta o desenvolvimento do Mediador Game, um jogo digital baseado em processos de negócio para apoiar o treinamento de processos, aplicado na mediação de conflitos do poder judiciário. O jogo foi projetado utilizando o método Play Your Process, desenvolvido em pesquisas anteriores, que descreve as etapas para transformar elementos de modelos de processos de negócio em elementos de design de jogos.

\section{Introdução}

A pesquisa apresentada neste artigo é um dos resultados de um projeto de iniciação tecnológica, inserido em um projeto de pesquisa do Grupo de Pesquisa e Inovação em Ciberdemocracia [CIBERDEM] $^{12}$, que propõe explorar o uso de jogos digitais para motivar e engajar profissionais a respeito de processos organizacionais e, ao mesmo tempo, habilitá-los a compreender sobre seu funcionamento.

O método Play Your Process [CLASSE et al. 2019a], desenvolvido pelo CIBERDEM, apoia a construção de jogos digitais baseados em processos de negócio. $\mathrm{O}$ método foi validado em contexto e demonstrou que jogadores, ao jogar um jogo baseado em processo de negócio, têm uma maior compreensão dos processos implementados no jogo.

Neste trabalho, abordamos o processo de seleção de mediadores em um Centro Judiciário de Solução de Conflitos e Cidadania ${ }^{3}$ (CEJUSC). Apresentaremos um protótipo - Mediador Game - desenvolvido com o objetivo de possibilitar ao jogador compreender o funcionamento do processo de seleção de mediadores, ao mesmo tempo que se diverte e aprende detalhes do processo.

\footnotetext{
${ }^{1}$ https://ciberdem.mack.com.br/

${ }^{2}$ Financiado pelo Fundo Mackpesquisa e pelo CNPq (313210/2019-5)/ (117355/2020-8)

${ }^{3}$ http://www.tjrj.jus.br/web/guest/institucional/mediacao/cejusc
} 


\section{Fundamentação Teórica}

A gestão de processos de negócio pode ser definida como a prática e a ciência de analisar como um trabalho é realizado dentro das organizações para assegurar resultados positivos e oportunidades de melhoria para execução das tarefas e alcance de objetivo [Dumas et al. 2018]. Uma área importante a ser considerada na gestão de processos é o treinamento de processos.

Pesquisas do CIBERDEM têm explorado o uso de jogos como uma alternativa para potencializar o treinamento de processos, bem como o entusiasmo e engajamento dos profissionais com este treinamento. Jogos digitais baseados em processos de negócio são um gênero de jogo que apresenta um processo de negócio de forma lúdica e permite aos jogadores compreenderem e aprenderem seu funcionamento de forma divertida e engajante [CLASSE et al. 2019b].

Este trabalho de iniciação tecnológica compreende a aplicação do método Play Your Process (PYP), que guia o designer na construção de jogos baseados em processos de negócio, desde sua conceitualização até a avaliação, por meio de etapas iterativas e com base nas informações obtidas em modelos de processos de negócio. O design do Mediador Game também é baseado em Schell [2009], que indica que existem quatro elementos básicos a serem considerados para o desenvolvimento de jogos digitais: estética, mecânicas, narrativa e tecnologia.

\section{Metodologia de Pesquisa}

A metodologia utilizada no projeto segue a abordagem de Design Science Research, que permite a contribuição simultânea para questões tanto científicas quanto tecnológicas, dando espaço para ações de desenvolvimento tecnológico e inovação [Pimentel et. al., 2017]. A metodologia envolve ciclos de problematização, design e a construção de uma solução para este cenário, sua demonstração de viabilidade, comunicação de resultados e refinamentos às características dos problemas e das soluções.

No que se refere à problematização, o jogo está inserido no contexto dos processos de mediação de conflitos do CEJUSC-RJ. Do processo completo de mediação de conflitos, recortamos o subprocesso de recepção de solicitações de mediação (Figura 1) para o desenvolvimento do jogo. Essa parte do processo é importante, haja vista que a seleção adequada de mediadores é fundamental para o sucesso da mediação do conflito.

Seguindo o PYP, os elementos do modelo do processo selecionado (Figura 1) foram mapeados para os elementos de design do jogo, gerando assim, o Game Design Document (GDD), que concebeu a base para o desenvolvimento do jogo relatado nesta pesquisa. A implementação do jogo foi realizada no software Construct $3^{4}$. Para a construção dos personagens foi utilizado os softwares Krita ${ }^{5}$,Piskel $^{6}$ e Canva ${ }^{7}$. O jogo funciona em Android (APK) a partir da versão 5.1.

\footnotetext{
${ }^{4}$ https://www.construct.net/en

${ }^{5}$ https://krita.br.uptodown.com/windows

${ }^{6}$ https://www.piskelapp.com/

${ }^{7}$ https://www.canva.com/pt_br/pro/
} 


\subsection{Design do Mediador Game}

O principal desafio do desenvolvimento do jogo está em como criar um mundo de jogo, mecânicas, dinâmicas e estética de forma alinhada com o modelo de processo de negócio (Figura 1), seguindo o GDD preliminar. De acordo com o PYP, os elementos do processo foram mapeados em elementos do jogo da seguinte forma: eventos ("Solicitação feita e conflito relatado", "TSM de ausência redigido" e "Mediador recepciona as partes") como eventos iniciais e finais no jogo; ator ("Secretária") como personagem e a Secretaria como cenário do jogo; atividades (vide figura) como tarefas ou fases do jogo; recursos ("DCP" e "SPE") como ferramentas para o jogador. Com o propósito de discutir o objetivo do jogo foi realizada uma reunião com designers e especialistas do processo.

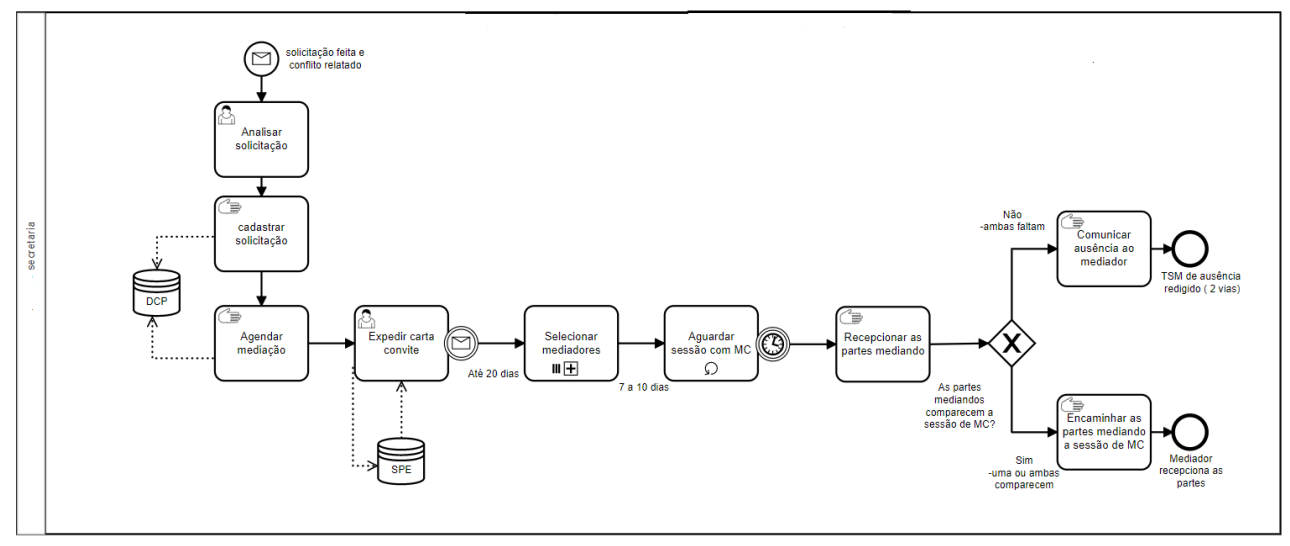

Figura 1. Processo de Mediação Cejusc

O mundo do jogo apresenta a situação de uma secretária que participa de todas as etapas do processo de mediação de conflitos, desde a chegada da mensagem do cidadão, solicitando a mediação, até encaminhar as partes (autora e ré) à sessão de mediação ou comunicar ausência ao mediador. Para iniciar o processo de mediação, é preciso ter uma solicitação e fazer sua análise. Após isso, é necessário o cadastro das informações das partes (Figura 2) para gerar o número do processo.

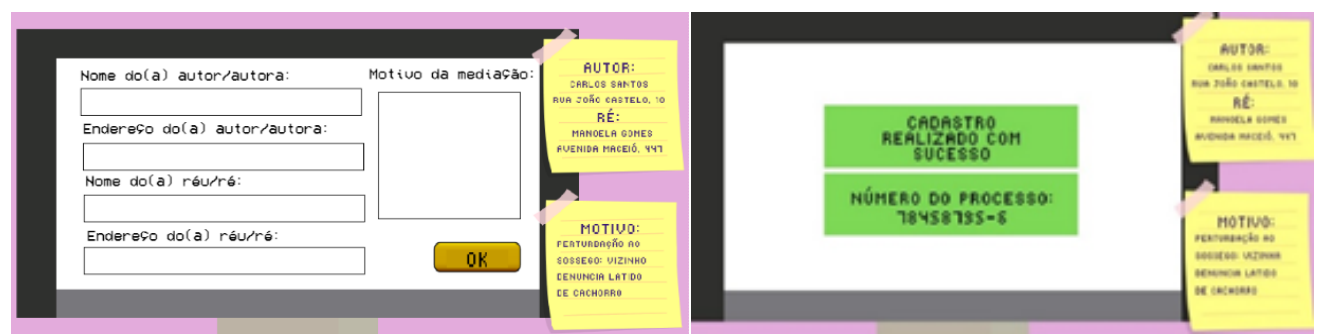

Figura 2. Layout Cadastro de solicitação

No cenário "Selecionar Mediador" (Figura 3), foi explorado um contexto de perguntas e respostas entre a secretária e um personagem da atividade. A secretária responde as perguntas sobre as informações necessárias e geradas da atividade do processo. Para as tarefas de "analisar solicitação" e "expedir carta-convite" foi desenvolvido um quiz, onde o jogador tem a opção de marcar três possíveis respostas, sendo apenas uma alternativa correta, ganhando pontos ao acertar. 


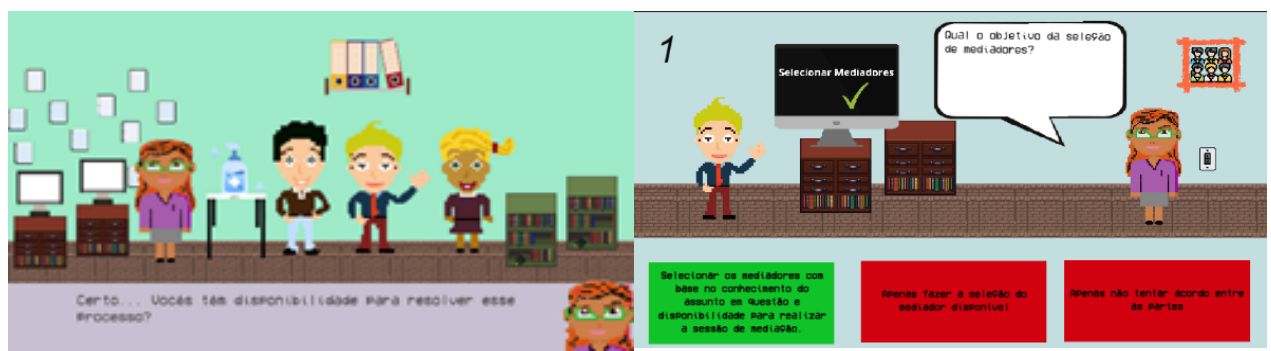

Figura 3. Seleção de Mediadores

Já no cenário "Recepcionar as partes" (Figura 4), o jogador pode escolher tanto ir para o cenário de "Comunicar ausência ao mediador", quanto "Encaminhar as partes à sessão de MC" quanto esses comparecem.

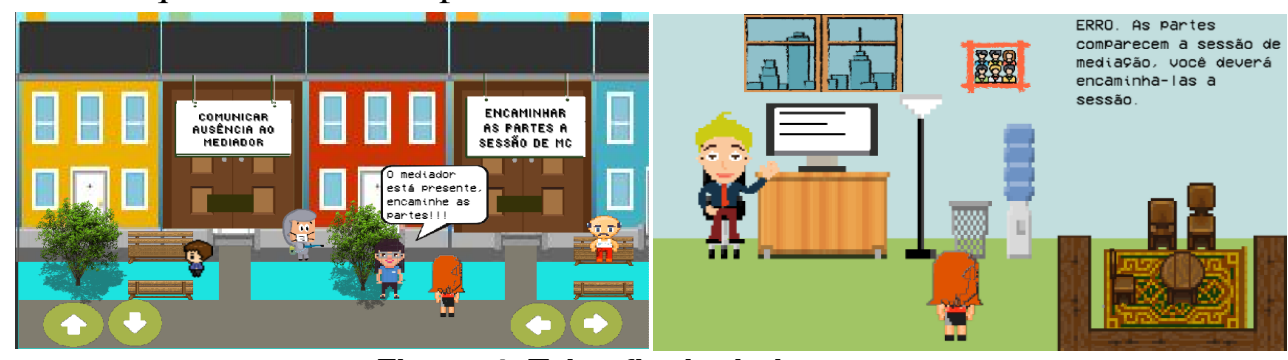

Figura 4. Telas finais do jogo

\section{Conclusão}

Neste artigo, apresentamos o design do Mediador Game, um jogo que explora as possibilidades de usar jogos digitais baseados em processos de negócio para treinamento de processos. Seu protótipo está em fase de avaliação, no contexto de uma pesquisa de mestrado do CIBERDEM, junto com especialistas no processo de mediação de conflitos do CEJUSC. Como trabalhos futuros sugere-se: aperfeiçoar o design, incluir novas versões, ambientes para o jogo e ajustar melhorias e acrescentar fases.

\section{Referências}

Classe, T. M., Araujo, R. M. D., Xexéo, G. B., and Siqueira, S. (2019a). "The play your process method for business process-based digital game design". In International Journal of Serious Games, p. 27-48.

Classe, Tadeu; XEXEO, Geraldo; ARAUJO, Renata. (2019b) "Jogos Digitais Baseados em Processos de Negócio”. SBGAMES. Rio de Janeiro.

Dumas, M., Rosa, M. L., Mendling, J., and Reijers, H. A. (2018). Fundamentals of Business Process Management. Springer, 2nd edition.

Pimentel, M., Fillipo, D., Calvão, L.A., Silva, A.R. (2017) Design Science Research: pesquisa científica para o desenvolvimento de artefatos inovadores. Em: Araujo, R.M. e Chueri, L.O.V. (eds) Da Pesquisa à Inovação: Visões e Interseções. Publ!t Soluções Editoriais

Schell, J. The Art of Game Design (2009) A Book of Lenses. Burlington, USA: Morgan Kaufmann Publishers \& Elsevier. 